\title{
Design and Simulation of three Phase three Wire Shunt Active Filter using Instantaneous PQ Theory
}

\author{
Tilak Giri, Ram Prasad Pandey, Sabin Bhandari, Sujan Moktan, Lagat Karki \\ Department of Electrical Engineering, Pulchowk Campus, IOE, Tribhuvan University, Nepal \\ Corresponding author: giritilak8@gmail.com,ramprajwol@pcampus.edu.np
}

Received: Nov 7, 2018

Revised: Dec 27, 2018

Accepted: Dec 29, 2018

\begin{abstract}
Due to intensive use of power converters and other non-linear loads, power quality is degrading. The presence of harmonics in the power lines result in greater power losses in distribution, interference problems in communication systems. Non linearity reduces the efficiency and power factor of the system. As the power factor reduces, the reactive power demanded from the supply increases which have no any contribution in energy transfer, so compensation is required. For this, shunt passive filter has been developed but it is bulky and frequency dependent and has many drawbacks. In contrast to passive filter, shunt active filter (SAF) has been developed which is smaller and has wide range of applications. In this paper, shunt active filter based on p-q theory is demonstrated for compensating reactive power and current harmonics. Simulation has been done with and without SAF and results are presented and ended with recommendation and conclusion. An effort is made to reduce the THD of the source current below 5\% (specified by IEEE).
\end{abstract}

Keywords: Harmonic current, Non-linear load, Power quality, P-Q Theory, Reactive power compensation, SAF

\section{Introduction}

Now-a-days, decadence of power quality is foremost issue of electrical society. In practice, utilization of switching device is increased in industrial as well as in domestic applications. Nonlinearity causes adverse effects on system efficiency, utility of the power supply, power factor, etc. Because of this, remedy is a dynamic filter. The every devices used during this research work are non-linear in nature as shown in Fig. 1.

The non-linear load draws non-sinusoidal current because they draw fundamental component as well as harmonics component. The value of THD should not exceed $5 \%$ as per standard. But in real case there is no pure linear load. In

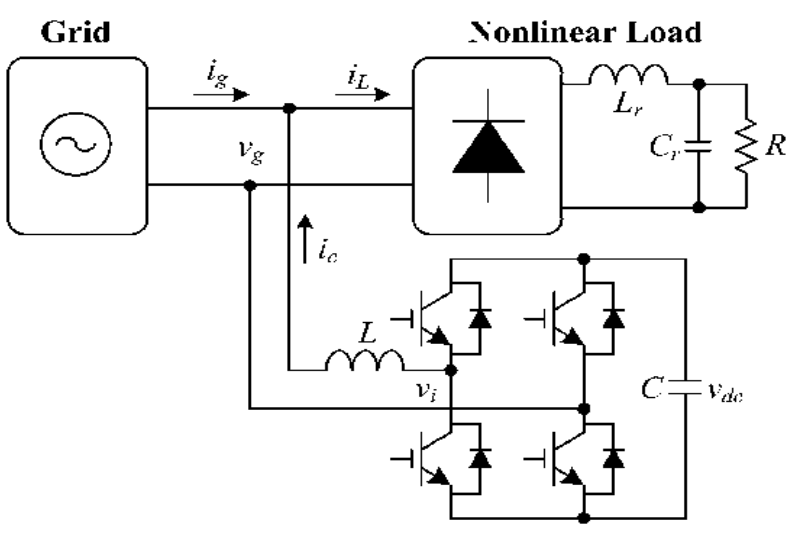

Fig. 1: Non-linear Load 
previous years, shunt passive filters were used as harmonic elimination technique due to their cheaper cost and ease of operation. But they face some major drawbacks of specific harmonic elimination, detuning, large size, series/parallel resonance, etc. To overcome these problems, active filter has been developed. It provides dual functions: harmonic and reactive power compensation in real time simultaneously. Based on the connection of the active filter, they are also classified as shunt and series active filter.

Shunt active filter, as shown in Fig. 2, is able to compensate for both current harmonics and reactive power whereas series active filter does not compensate for load current harmonics but it acts as high-impedance to the current harmonics coming from the power source side $[1,5]$. Another solution to solve the load current harmonics is to use a shunt active filter together with the series active filter, so that both load voltages and the supplied currents are guaranteed to have sinusoidal waveforms [2].

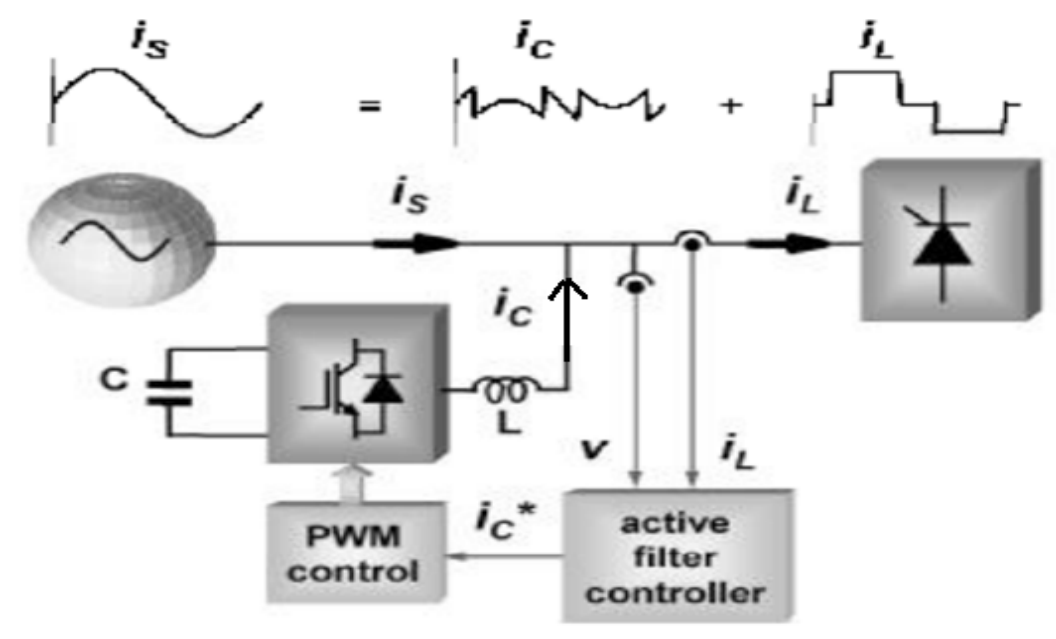

Fig. 2: Block Diagram of Shunt Active Filter

Here, three phase voltage source is supplying power to the three phase non-linear load with SAF connected in parallel. ' $I_{S}$ ' represents source current which is sinusoidal, ' ${ }_{L}$ ' represents load current which is non- sinusoidal and ' $\mathrm{I}_{\mathrm{C}}$ ' represents compensating current which is in phase opposition but has equal magnitude to that of harmonic current present in load current and injected by SAF to cancel out harmonic component. In this paper, work is done on the shunt active filter to compensate the current harmonic and reactive power and comparative analysis of the total harmonics distortion (THD) and reactive power compensation of the system has been done.

\section{P-Q Theory}

In 1983, Akagi et al. [3,4] have proposed the "The Generalized Theory of the Instantaneous Reactive Power in Three-Phase Circuits", also known as instantaneous power theory, or p-q theory. It is based on set of instantaneous power defined in the time domain. The first version was published in July 1982 in a local journal of Japan and later published in IEEE. They can be used either in three phase system three wire system or four wire system. It is valid not only in steady state but also transient state. 
The PQ-theory consists of $\alpha \beta 0$ transformation. It converts 3-phase voltages and currents to the corresponding $\alpha \beta 0$ reference frame. The three phase axis is converted to two phase axis where zero sequence components is not related to $\alpha$ and $\beta$ axis. The mathematical representations of all the Clarke transformation are

$$
\left[\begin{array}{l}
v_{o} \\
v_{\beta} \\
v_{\beta}
\end{array}\right]=\sqrt{\frac{2}{3}}\left[\begin{array}{ccc}
\frac{1}{\sqrt{2}} & \frac{1}{\sqrt{2}} & \frac{1}{\sqrt{2}} \\
1 & \frac{-1}{2} & \frac{-1}{2} \\
0 & \frac{\sqrt{3}}{2} & \frac{-\sqrt{3}}{2}
\end{array}\right]\left[\begin{array}{l}
v_{a} \\
v_{b} \\
v_{c}
\end{array}\right]
$$

The above matrices convert the $\alpha \beta 0$ voltage axis to $\alpha \beta 0$ voltage axis.

$$
\left[\begin{array}{l}
i_{o} \\
i_{\alpha} \\
i_{\beta}
\end{array}\right]=\left[\begin{array}{ccc}
\frac{1}{\sqrt{2}} & \frac{1}{\sqrt{2}} & \frac{1}{\sqrt{2}} \\
1 & \frac{-1}{2} & \frac{-1}{2} \\
0 & \frac{\sqrt{3}}{2} & \frac{-\sqrt{3}}{2}
\end{array}\right]\left[\begin{array}{l}
i_{a} \\
i_{b} \\
i_{c}
\end{array}\right]
$$

Similarly, above matrices convert abc current axis to $\alpha \beta 0$ current axis.

$$
\left[\begin{array}{c}
p_{0} \\
p \\
q
\end{array}\right]=\sqrt{\frac{2}{3}}\left[\begin{array}{ccc}
v_{0} & 0 & 0 \\
0 & v_{\alpha} & v_{\beta} \\
0 & v_{\beta} & v_{\alpha}
\end{array}\right]\left[\begin{array}{c}
i_{0} \\
i_{\alpha} \\
i_{\beta}
\end{array}\right]
$$

This mathematical expression (3) is used to calculate the instantaneous value of zero sequence power $\left(\mathrm{p}_{\mathrm{o}}\right)$, active power $(\mathrm{p})$ and reactive power $(\mathrm{q})$ in $\alpha \beta$ axis.

$$
\left[\begin{array}{c}
I_{\alpha c} \\
I_{c \beta}
\end{array}\right]=\frac{1}{v_{\alpha}^{2}+v_{\beta}^{2}}\left[\begin{array}{cc}
v_{\alpha} & v_{\beta} \\
v_{\beta} & -v_{\alpha}
\end{array}\right]\left[\begin{array}{l}
\widetilde{-p} \\
-q
\end{array}\right]
$$

Here, $\tilde{p}=\mathrm{P}-\mathrm{P}_{\mathrm{dc}}$

where, $\quad P=$ total instantaneous power, $P_{d c}=$ average power and $\tilde{p}=$ oscillating power $I_{\alpha c}=$ Compensating current in $\alpha$-axis and $I_{\beta c}=$ Compensating current in $\beta$-axis

Here, PQ-theory tracks the power in order to produce compensating current $I_{\alpha c}$ and $I_{\beta c}$.

$$
\left[\begin{array}{c}
i^{*}{ }^{*}{ }{ }^{*}{ }_{c b} \\
i^{*}{ }^{*}
\end{array}\right]=\sqrt{\frac{2}{3}}\left[\begin{array}{ccc}
1 & 1 & 0 \\
1 & \frac{-1}{2} & \frac{\sqrt{3}}{2} \\
1 & \frac{-1}{2} & \frac{-\sqrt{3}}{2}
\end{array}\right]\left[\begin{array}{c}
\text { Io } \\
\text { I } \alpha c \\
\text { I } \beta c
\end{array}\right]
$$

These equations are used to carry out the simulation of SAF with the help of embedded function block.

\section{MATLAB Simulation}

The overall model of system is shown in Fig. 3. We used three phase Breaker to break the SAF from the transmission line at the starting of the simulation. The model is run for $3 \mathrm{sec}$. After 1.5 
$\mathrm{sec}, \mathrm{SAF}$ is connected to the transmission line to compensate current harmonic and reactive power consumed by load. Shunt active filter block calculates the current harmonic and reactive power to be injected taking the load current and load voltage as references. During sudden decrease in load, extra active power will be flow through SAF branch. Some power will be dissipated across resistance of the coupler and remaining portion will be responsible for raising the capacitor voltage. Similarly, during sudden increase in load, extra active power will be supplied by the SAF, thus by discharging the previously charged capacitor.

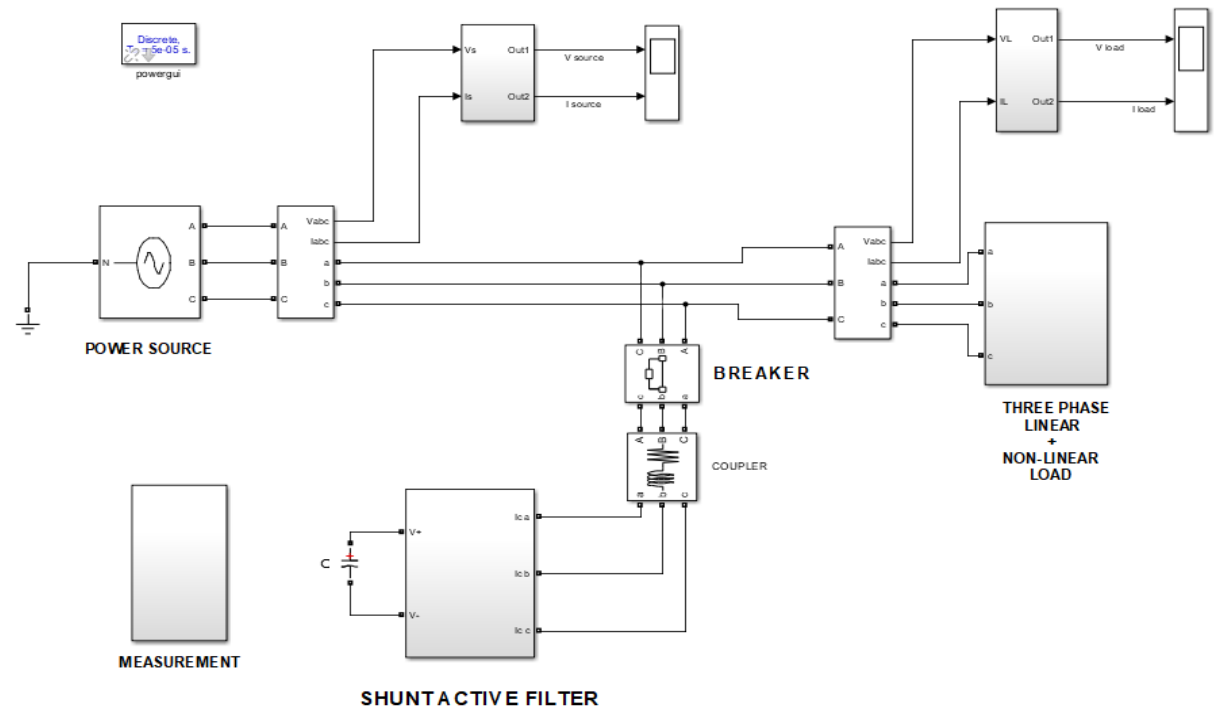

Fig. 3: Overall Simulation Model of the system

\section{Result and Discussion}

Simulation results are presented below. Fig. 4 shows the waveform of source voltage and current before and after compensation.
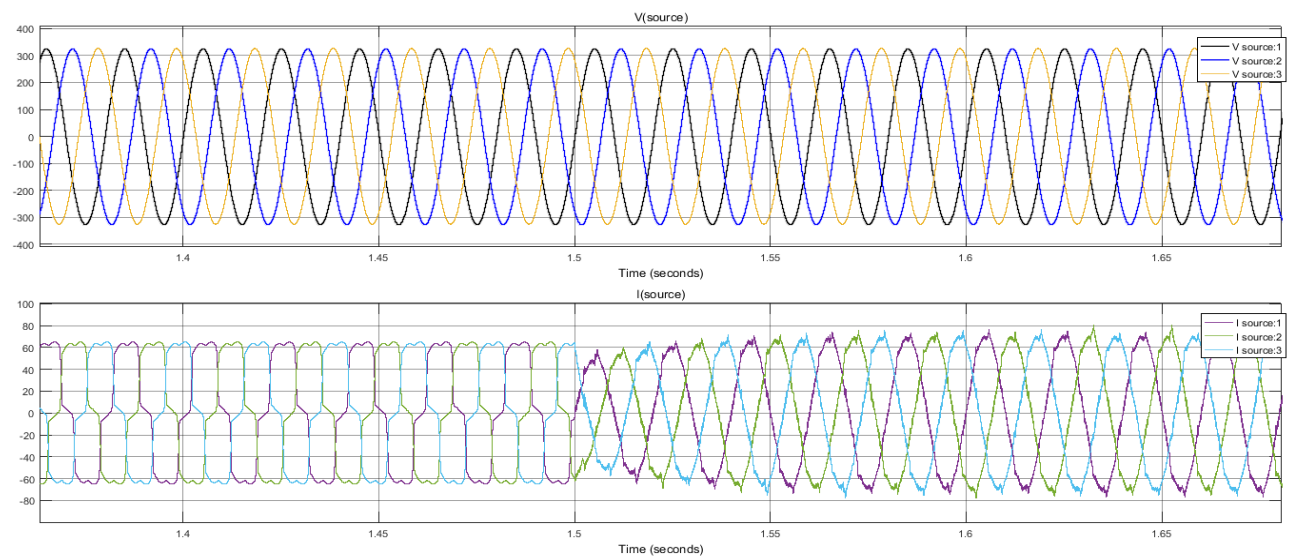

Fig. 4: Waveform of Source Voltage and Current before and after compensation

The Fourier analysis of source current before using shunt active filter(SAF) and after using SAF are shown in Fig. 5 and Fig. 6 respectively. 


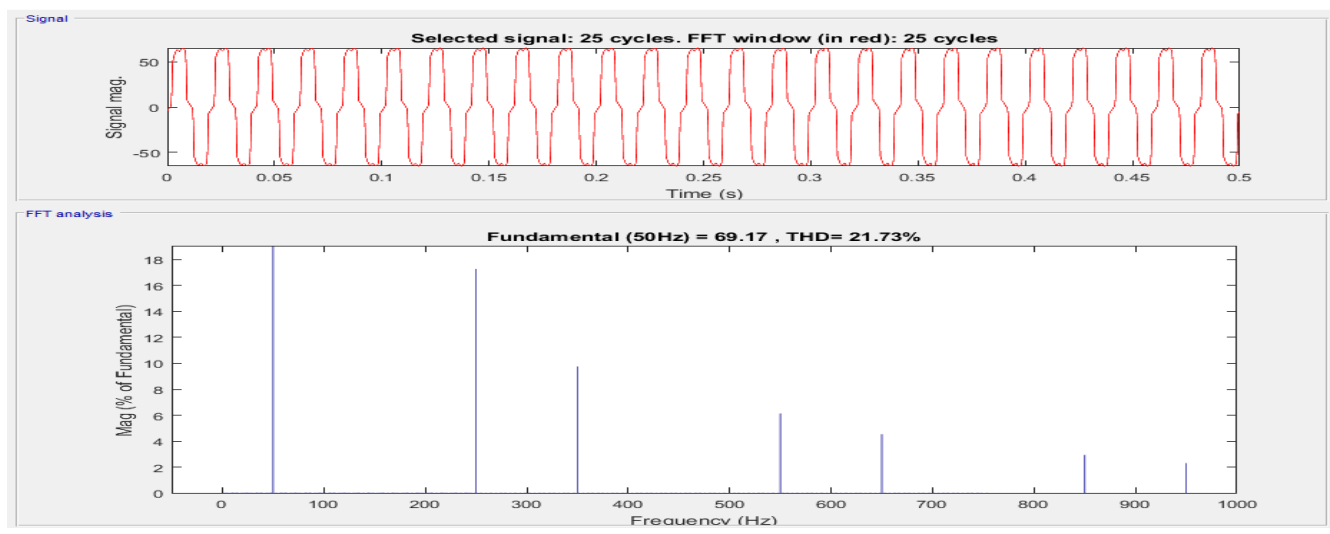

Fig. 5: FFT analysis of the source current before using SAF

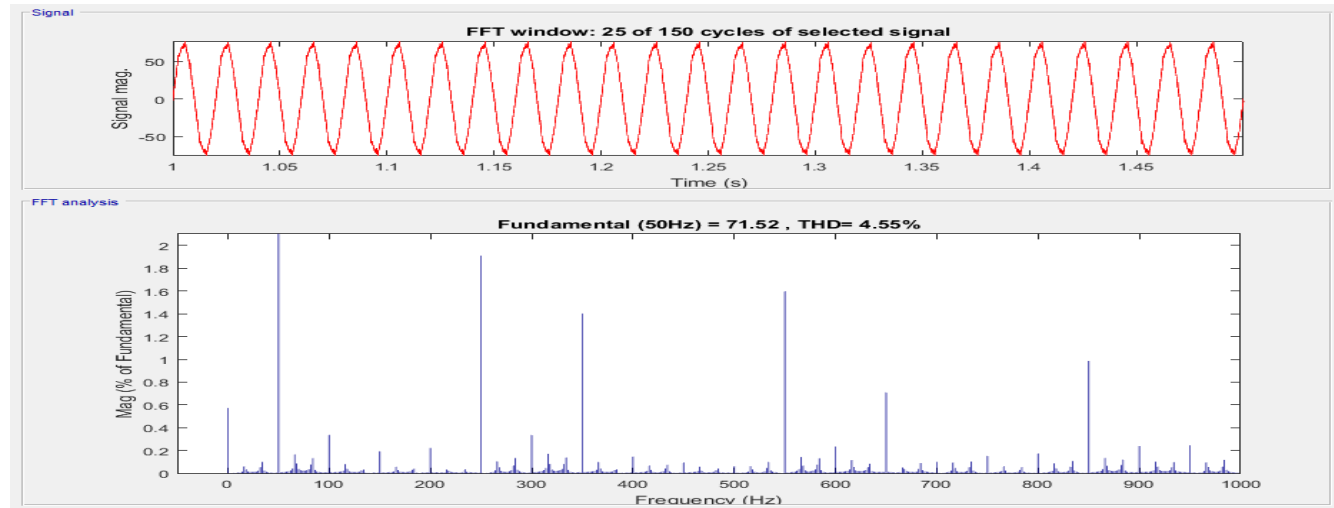

Fig. 6: FFT analysis of the source current after using SAF

From results, it is clear that THD of the source current is within the limit $(<5 \%)$ specified by IEEE standard.

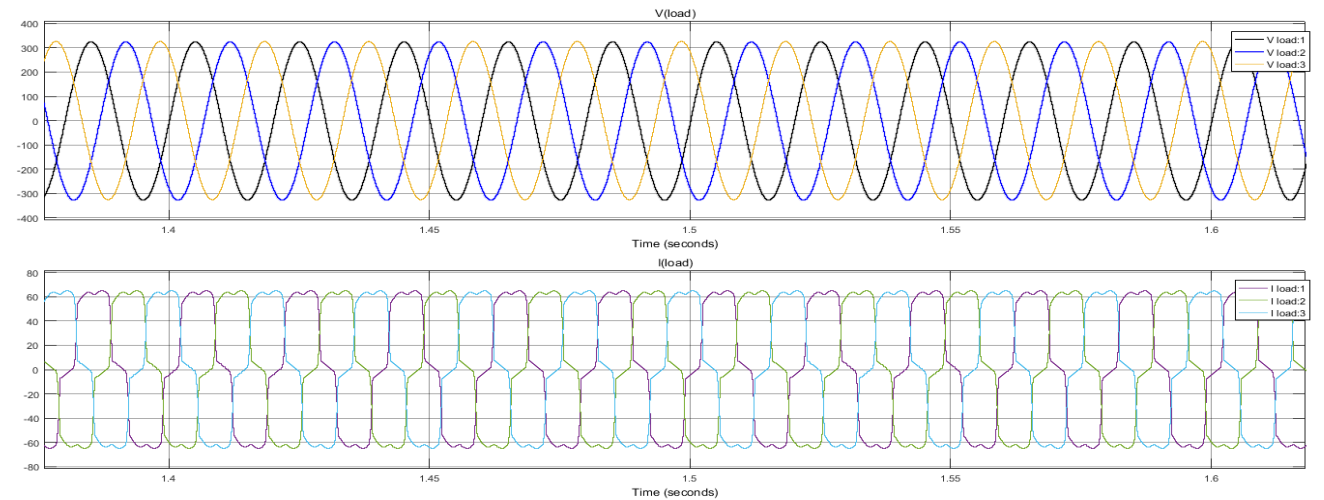

Fig. 7: Waveform of Load Voltage and Current after and before compensation

It is clear that there is no any change in voltage and current of load after using SAF. Result shows that the SAF supplies the reactive power consumed by the load and source supplies the active power only consumed by the load after compensation. Comparison is shown in Table 1 below. 


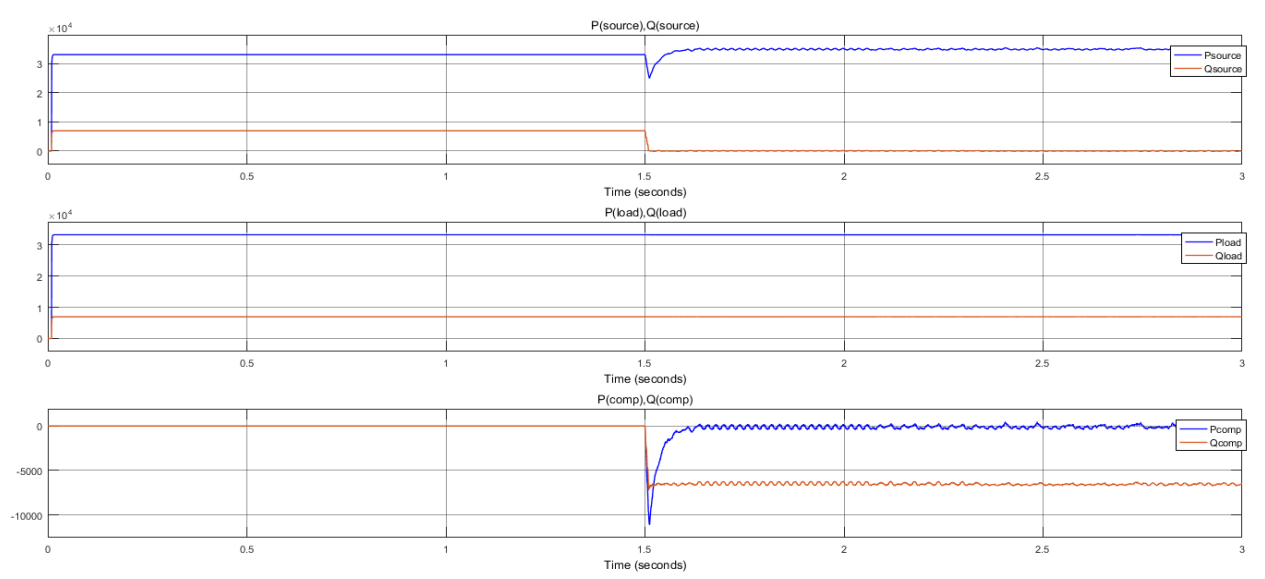

Fig. 8: Active and Reactive Power of Source, Load and Compensator

Table 1: Comparison Based on Connection of Filter

\begin{tabular}{|l|l|l|}
\hline Quantity & Without SAF & With SAF \\
\hline THD & $21.73 \%$ & $4.55 \%$ \\
\hline Reactive Power & 6600 Var & 0 \\
\hline
\end{tabular}

The value of THD is decreased from $21.73 \%$ to $4.55 \%$. Even the Reactive power supplied by source is totally compensated after the involvement of SAF.

\section{Conclusion}

This paper presents the fact that the current harmonic and reactive power of the non- linear loads are becoming a serious problem in power system. To overcome this problem, SAF has been developed. In this paper, simulation with or without SAF has been carried out and finally result and analysis of the outcomes has been presented. Result shows that the SAF based on p-q theory is able to compensate the current harmonic and reactive power of the non- linear load, thus it is powerful tool.

\section{References}

[1] Afonso J, Couto C and Martins J (2000), Active Filters with Control Based on the p-q Theory, IEEE Industrial Electronics Society Newsletter, 47: 5-10.

[2] Akagi H, Watanabe EH and Aredes M (2007), Instantaneous power theory and applications to power conditioning, IEEE Press, Piscataway, USA.

[3] Akagi H, Kanazawa Y, Nabae A (1983), Generalized Theory of the Instantaneous Reactive Power in Three- Phase Circuits, Int. Power Electronics Conf., Tokyo, Japan, 1375-1386.

[4] Akagi H, Kanazawa Y and Nabae A (1984), Instantaneous Reactive Power Compensator Comprising Switching Devices without Energy Storage Components, IEEE Trans. Industry Applic., 20: 625-630.

[5] Kumar DP (2007), Investigation on shunt active power filter for power quality improvement, Department of Electrical Engineering, National Institute of Technology, Rourkela, India. 